\title{
UNLIMITED POTENTIALS OF CARBON: DIFFERENT STRUCTURES AND USES (A REVIEW)
}

\author{
Onyeka Stanislaus Okwundu ${ }^{* 1,2}$, Emmanuel Uche Aniekwe ${ }^{2}$, \\ Chinaza Emmanuel Nwanno 3
}

\author{
${ }^{I}$ Department of Chemical and Petrochemical Engineering, Egypt-Japan \\ University of Science and Technology (E-JUST), Egypt. \\ ${ }^{2}$ Department of Chemical Engineering, University of Benin, Nigeria. \\ ${ }^{3}$ Department of Physics, University of Benin, Nigeria.
}

Received 30.09.2018

Accepted 02.10.2018

\begin{abstract}
Carbon is a unique chemical element whose different forms or allotropes are inexhaustible in number. It has been in use since antiquity and now, the possibility of manipulating the lattice structure of its crystalline allotropes, offers it unlimited advanced applications. This review aims at demonstrating certain aspects of engineering materials in different applications. Various structures of some identified allotropes of carbon, respective properties and uses of the allotropes were reviewed. Amorphous carbon materials find application mainly as fuels and sometimes as parent materials for the synthesis of more useful chemicals. Their limited application was ascribed to their unstable irregular patterned structure which cannot be manipulated easily to meet further needs. Structurally, carbon exists in the $\mathrm{sp}^{3}$ and $\mathrm{sp}^{2}$ hybridized state in the crystal lattice of its crystalline allotropes. Due to the salient features of its allotropes, carbon finds application in energy generation and storage, optics, electronics, optoelectronics, electrocatalysis, corrosion control, bio-sensing (diagnostics), sensing, agriculture, water treatment, the production of composite materials with unique properties and more. There is no limit to the application of carbon. It was recommended that renewable and sustainable alternative precursors for the synthesis of carbon nanomaterials with adequate control of crystal growth be sought for.
\end{abstract}

\footnotetext{
*Corresponding author: Onyeka Stanislaus Okwundu, okwundu.onyeka@ejust.edu.eg; onyeka.okwundu@eng.uniben.edu
} 


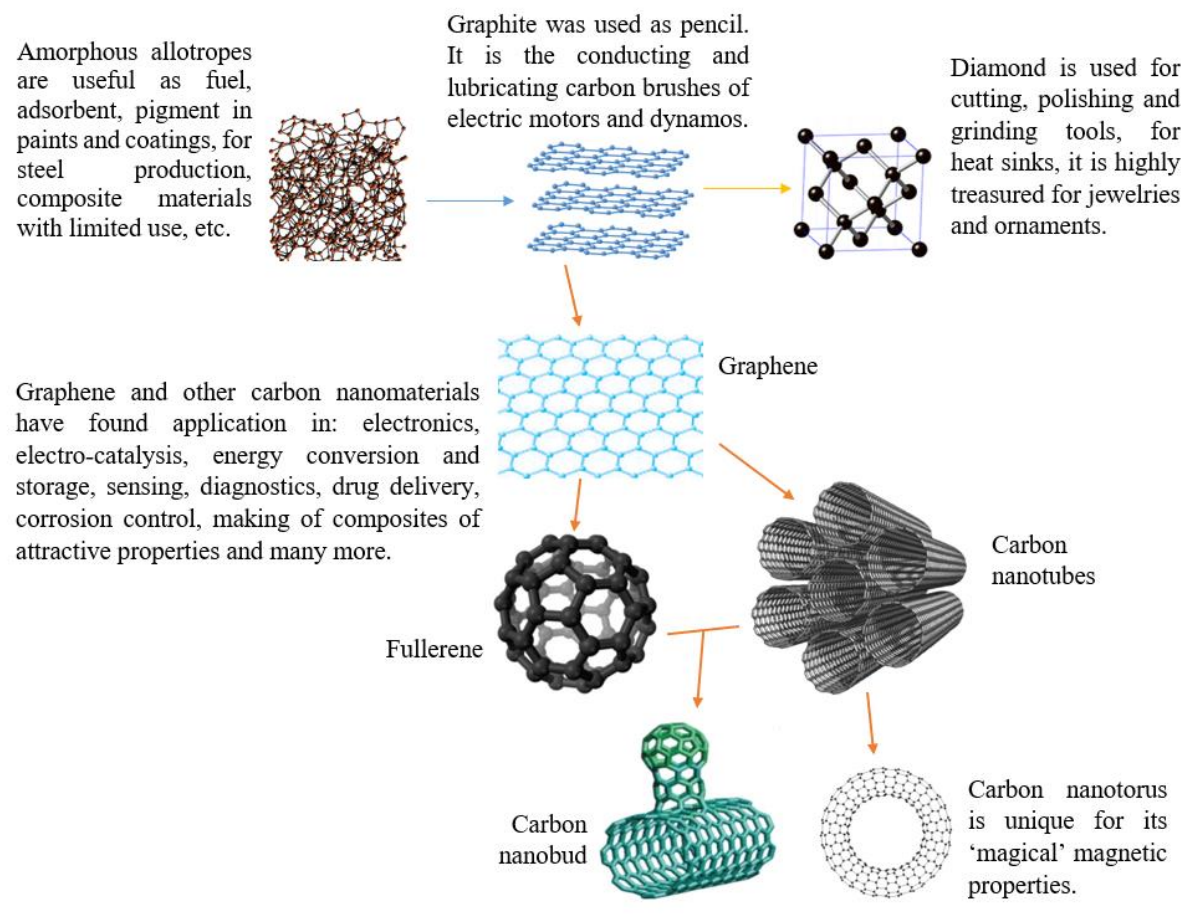

Keywords: Allotropes of carbon; structures of carbon; applications of carbon; amorphous carbon; carbon nanomaterials.

\section{Introduction}

Of all chemical elements known to man, carbon, the sixth element in the periodic table with an average atomic mass of 12 amu (usually represented as ${ }_{6}^{12} \mathrm{C}$ ), is distinct and essential on earth. It is reported to be: universally the 6th commonest element, the 4th commonest in the solar system and the 17th in earth crust [1-3]. After oxygen, carbon is notably the most prevalent element in our body, contributing $18 \%$ of the body weight [4]. Quoting from Loos [2]: "Carbon is the most important element found in living organisms. Life, as we know it, would not exist without carbon atoms". The uniqueness of carbon comes from the fact that it can form single, double or triple bonds; it has exceptional ability to catenate (bond with one another), forming cyclic or acyclic chains; it can form straight or branched chains; it can also bond with other non-metallic elements $[1,5]$. 


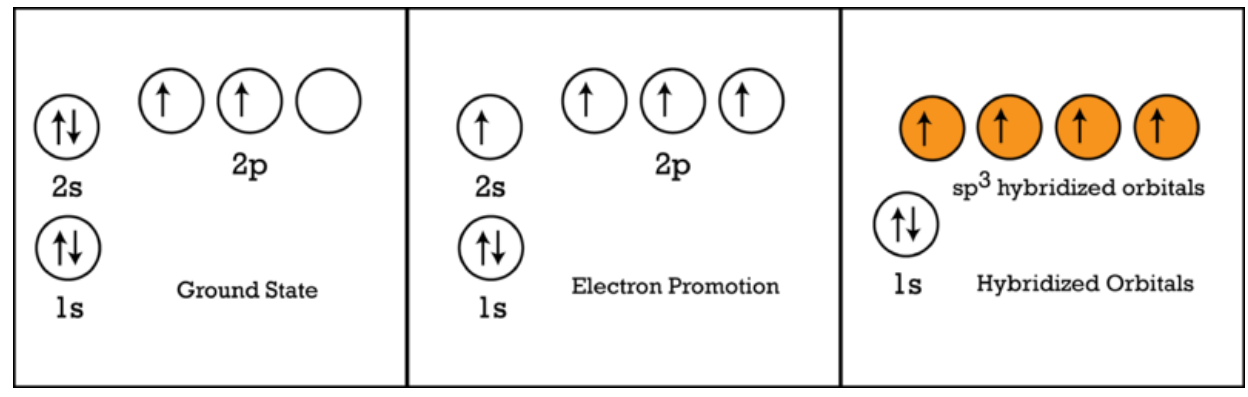

Fig. 1. Steps in $s^{3}$ hybridization of carbon [5].

Considering the electronic configuration of carbon, we briefly introduce the concept of hybridization as that would be useful in describing some structures afterward. Fig. 1 illustrates the steps in $\mathrm{sp}^{3}$ hybridization of carbon [5]. The s-p-d-f electronic configuration format shows that the six electrons in a carbon atom are arranged in order of increasing energy, from $1 \mathrm{~s}$ through $2 \mathrm{~s}$, to $2 \mathrm{p}$ orbitals at the ground state as shown on the left side of Fig. 1. In the excited state, there is electron promotion to higher energy orbital (from $2 \mathrm{~s}$ to $2 \mathrm{p}_{\mathrm{z}}$ ), as shown in the middle of the figure. Hybridization is the mixing of orbitals of different energy levels to form hybrid orbitals of equal energy level [6]. When the $2 \mathrm{~s}, 2 \mathrm{p}_{x}, 2 \mathrm{p}_{y}$ and $2 \mathrm{p}_{\mathrm{z}}$ orbitals are hybridized, as illustrated on the right side of Fig. 1, the carbon atom is said to have undergone $\mathrm{sp}^{3}$ hybridization. If only the $2 \mathrm{~s}$ and two $2 \mathrm{p}$ orbitals are hybridized, it is termed $\mathrm{sp}^{2}$ hybridization. Similarly, it is sp hybridized if only one of the p orbitals is involved. The electrons in the hybridized orbitals participate in the formation of sigma bonds while those in un-hybridized orbitals form pi bonds. The $2 s$ and $2 p$ orbitals of carbon can be hybridized to enable single, double or triple bonds formation via $\mathrm{sp}^{3}, \mathrm{sp}^{2}$ or $\mathrm{sp}$ hybridizations respectively.

Carbon, in the elemental form, is sparsely abundant as it constitutes just $0.2 \%$ of the earth [3, 7]. Notwithstanding, the science of carbon as an element (rather than just compound), is still trending. Some chemical elements exist in more than one form - this phenomenon is termed allotropy, and the various forms are called allotropes [5, 8]. By convention, carbon naturally has three allotropes, namely: amorphous carbon (such as coke and coal), the crystalline graphite and diamond [6]. Taking advantage of carbon's valence electrons and one of its unique nature - carbon's ability to covalently bond with fellow carbon - a lot of other carbon allotropes (in crystalline form) have been discovered, thereby making it the chemical element with highest number of known allotropes, in comparison to every other materials $[1,9]$.

Furthermore, in the nano-world (nanotechnology, materials science, engineering, and other fields of study alike), nanostructures of elemental carbon have been identified in 0-, 1-, 2- and 3-dimensions, and found to consist of carbon allotropes, such as: graphite, graphene, carbon nanotubes, activated carbon, and the commonest of fullerenes, the buckminsterfullerene [2], 9-13]. Nowadays, the interest of many researchers is aroused and geared towards nanotechnology as a result of the potentials of generating entirely new materials with exciting features from existing ones by mere alteration of size and/or shape; for several reasons, nanomaterials fit into diverse applications.

In the science of materials, we seek to relate the properties of materials to their respective compositions and structures. Moreover, of course, remarkable properties of a 
material determine its applicability. As a result, this review is aimed at demonstrating certain aspects of engineering materials in different applications; as achieved via the following objectives: to assess the various structures of carbon allotropes; to assess the respective properties of the allotropes of carbon and most importantly, to state their respective uses.

\section{Allotropes of Carbon: Structures, Properties and Uses}

\subsection{The Allotropes of Carbon}

Allotropy of carbon arises from the variation in the order of carbon atoms in a solid piece. Elemental carbon can therefore either exist in the amorphous or crystalline form in the solid state, just like sulfur and phosphorus [14, 15].

\subsubsection{Amorphous Allotropes of Carbon}

Although not even one of the amorphous allotropes has been identified in the pure (100\% carbon) state, the various kinds of amorphous carbon possess different properties and therefore deserve to be considered each as an allotrope, preferably they are grouped as one, the amorphous allotropes [15]. The amorphous forms of carbon are usually neglected, perhaps because their structures cannot be manipulated like the crystalline allotropes; hence, they do not appeal to the interest of researchers.
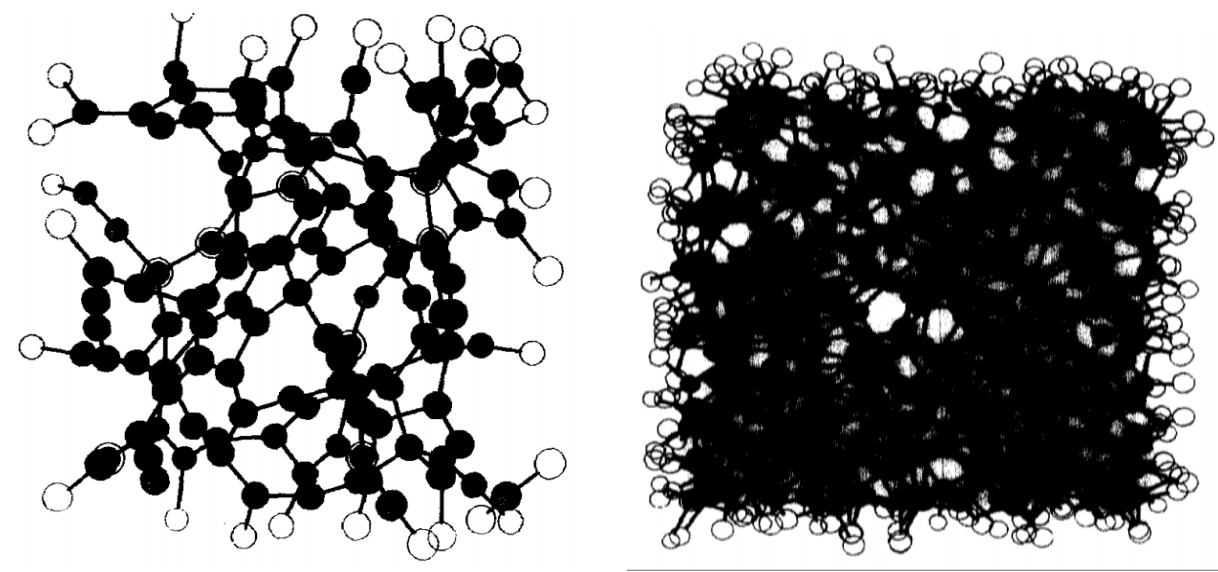

Fig. 2. Structural models of amorphous carbon generated from different precursors at different conditions of preparation [16].

Considering the structure - amorphous carbon lacks long-range consistency in the arrangement of atoms in a solid piece. There may be a bit of orderliness in the arrangement of atoms, but only on a short range. Fig. 2 shows two structural models of amorphous carbon generated from different precursors at different conditions of preparation [16]. The figure would serve as a representation for all the amorphous allotropes, as they each have no definite general structure. According to Kouchi [17], Frauenheim et al. [16] and Robertson [18], it has been observed via electron energy loss spectroscopy, that the chemical bonds existing among amorphous carbon atoms are formed from both $\mathrm{sp}^{2}$ and $\mathrm{sp}^{3}$ hybridization with many fractions of dangling or unstable bonds. Thermodynamically, amorphous allotropes of carbon are known to be in the metastable state, making their $\mathrm{sp}^{2}$ to $\mathrm{sp}^{3}$ hybridized bond ratio to vary according to the 
surrounding condition. The conditions and methods of forming amorphous allotropes of carbon, significantly influence their properties $[16,17]$. Their unstable (dangling) bonds may be made stable via the addition of hydrogen to terminate the dangling pi bonds [18]. The common amorphous allotropes of carbon include coal, charcoal, lamp black, carbon black, carbon fibers and coke.

\subsubsection{Coal}

Naturally, coal is available as a fossil material, formed via some natural processes like anaerobic decomposition of biomass amassed over geologic prehistory. It can be made from wood by subjecting the wood to anaerobic treatment at high temperature and pressure - a process known as carbonization of wood. Coal may be considered as: peat (if the carbon content is about 0.6 times the total mass), lignite (if it is brown and soft, composing of about 0.67 carbon by mass), bituminous (if it contains about 0.88 carbon by mass, typical of the coal used for domestic purposes), or anthracite (if it is hard, tough and has about 0.94 of its mass as carbon - this is the purest form of coal). In addition to carbon, coal also contains hydrogen, oxygen, and traces of nitrogen, sulfur, phosphorus, with impurities $[6,14,19]$.

Coal can be distilled destructively to yield some useful products which include coal gas, ammoniacal liquor, coal tar, and even another allotrope, coke. Industrially, it is used as fuel in steel plants to fire furnaces and power generation as heating fuel for the steam boilers. At homes, it also serves as fuel for cooking and warming houses during winter seasons. Fuel gases (producer gas and water gas) can be synthesized from coal. Crystalline graphite can be synthesized from coal too. It can be hydrogenated under controlled conditions to give synthetic petrol $[6,19]$.

\subsubsection{Charcoal}

Much like coal but under less severe conditions, charcoal is formed by heating biomass (including wood, sugar, nut shells, bones, blood, and even horns) in a controlled aerobic system at ambient pressure, while allowing volatile flue or exhaust gases to escape; the resulting solid residue is charcoal. Based on the source of precursor material, charcoal may be wood charcoal, animal charcoal, sugar charcoal, etc. [6, 15].

Wood charcoal is black, brittle and very porous; therefore, it makes a good adsorbent. In the powdered form, it is employed in the adsorption of poisonous gases from the polluted air (gas mask) and colorants from solutions. It also serves as a reducing agent. Domestically, charcoal is used as fuel $[14,19]$.

Animal charcoal from bones has about $11 \%$ amorphous carbon content with the rest predominantly comprising of calcium and magnesium compounds. The blood counterpart, blood charcoal is produced when blood is evaporated in the presence of potassium trioxocarbonate, ignited and charred; then the resulting charred residue is washed with water and $\mathrm{HCl}$ and still ignited again [20]. Potassium trioxocarbonate serves to furnish a substrate onto which the synthesized carbonaceous material is deposited. The animal charcoal can be activated by mixing the precursor material with sugar, before the synthesis. Animal charcoal is popularly known for its ability to purify solutions via adsorption. A typical example is the decolorization of raw brown sugar [6]. It is also useful in removing: indigo, litmus, iodine, the coloring-matter of red wine, the brown matter of peaty water or sewage, certain basic salts from solution, as well as fusel oil from alcohol. Its uses also extend to stringent principles. In medicine, Roberts in 1896 [21], employed animal charcoal to filter urine in the course of testing for sugar. Unique adsorbent nature of animal charcoal is used for filtering water; also, in the laboratory for 
purifying organic compounds by removing the tarry matter which is frequently formed with them [20]. Animal charcoal is also employed technically for purifying paraffin and glycerol, and the dusty particulate form is employed in making ivory-black and blacking. When the activity of the charcoal is depleted, it may be regenerated by igniting or treating it with reagents [22].

The purest of the amorphous allotropes of carbon is the sugar charcoal [6], and it is prepared by controlled heating of sugar in anaerobic condition. When the precursor material is crushed to a powder of about 5-micrometer particle size and synthesized at about $730{ }^{\circ} \mathrm{C}$ under vacuum, well-activated sugar charcoal is achieved. In the activated state, sugar charcoal has unimaginably high adsorption capacity and therefore makes a very good adsorbent [14].

\subsubsection{Lampblack}

Lampblack is black colored with a smooth, soft appearance. The velvety black matter is made via vapor (flue gas) deposition by burning carbon-rich tar and lipids (usually vegetable oils) under a limited supply of air and directing the flue gas through the desired adsorbent substrate.

It finds application in the manufacture of Indian ink, carbon papers, varnishes, paint (as pigment), and printers ink [14, 19]; of course, when employed in any of these materials production, it is meant to impart its inherent black color, somewhat reasonable bluish undertone is usually obtained [23].

\subsubsection{Carbon black}

Similar to lamp black but with the lighter precursor, burning of natural gas under limited air supply and depositing the solid content of resulting flue gas gives carbon black. It is usually scratched off from the substrate onto which it is deposited and packaged in sack bags. It is not as greasy as the lampblack.

It has replaced lamp black in several applications. It is mainly used in the manufacture of automobile tires, where it is blended with rubber to form a composite [14, 19]. Report from Orion [23] shows that carbon black pigments are useful in making paints and coatings for masstone coloration, and tinting of white or colored coatings, as well as many other types of coating applications, from industrial and automotive to decorative paints and transparent coloration.

\subsubsection{Carbon fibers}

These are non-graphitizing (that which cannot be modified to graphite) amorphous carbon that can be made from fibrous materials such as polyacrylonitrile fibers via carbonization process [18] or directly from gaseous hydrocarbon like methane [24]. Some graphitizing carbon fiber materials, synthesized by vapor deposition are however classified by Inagaki [25]. Carbon fibers contain at least $90 \%$ carbon [26]. It is revealed via electron microscopy, that carbon fibers are anisotropic in nature and are predominantly made up of long chains of carbon atoms; the fiber is a long, thin strand, about 5 to 10 micron in diameter [26] and length greater than 0.1 micron; the strands of carbon fibers preferentially align themselves parallel to each other as illustrated schematically in Fig. 3 [18]. According to Zoltek [27], the carbon atoms are bonded together in microscopic crystals which are aligned parallel to the long fiber axis. The crystal alignment makes the material to be incredibly strong for its size (lightweight) and even when heated to temperatures well above $2000{ }^{\circ} \mathrm{C}$; the fiber maintains these properties [28]. Robertson [18] also noted that carbon fibers are relevant due to their resilient strength. Since material strength is the remarkable property of carbon fiber, 
classification of the material is based on its tensile modulus, and by so doing, Zoltek [27] found via comparison, that the strongest grade of carbon fiber is about ten times stronger than steel, while being five times lighter in weight. Also, it is noted that they have the most superior fatigue properties when compared to all other metallic structures known, and when the suitable resin is used in conjunction, they prove to be among the most corrosion-resistant materials [27].

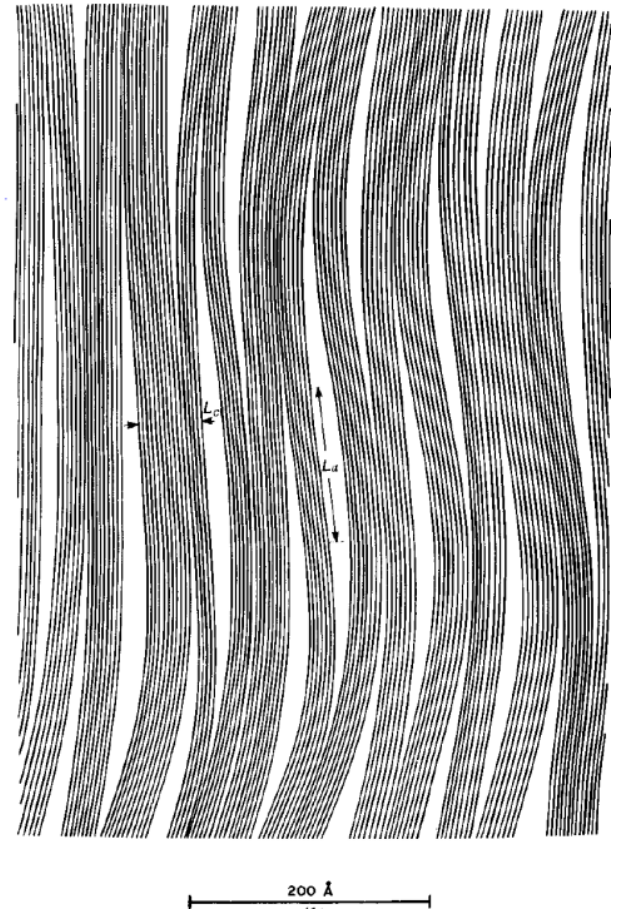

Fig. 3. Schematic structural features of carbon fiber [18].

Due to their extreme strength, they are used for imparting strength to composite materials [18]; its light weight is also of interest to manufacturers. The fibers come in different forms and can be manipulated to suit particular applications; for instance, thousands of carbon fiber may be collectively twisted to yield yarn, and this may be woven into fabric or even used like that, fabric or yarn can as well be used for different composite materials by winding or molding it into shape with epoxy [27]. Light weighted and high strength composite materials made of this fiber are in turn useful in the manufacture of some vital parts of aircraft and spacecraft, bodies of racing car, shafts of golf club, frames of bicycle, bodies, and springs of automobile, masts of sailing boats, rods for fishing, etc. [27]. The YouTube video [29] describes how carbon fiber is utilized in the manufacture of car parts, while Fig. 4 shows the image of a car bonnet made of this material [30]. Since the internal structure of carbon fiber dictates the materials performance; materials of more excellent performance can be made with carbon nanotubes which have perfect lattice structure but unfortunately, carbon nanotubes and the likes have not been successfully produced in such a large quantity to displace carbon fiber in certain vital mass production-applications like manufacture of airplanes and 
satellites [24]. Attempts have also been made to use carbon fiber as a flame retardant in textile reinforced composites [31].

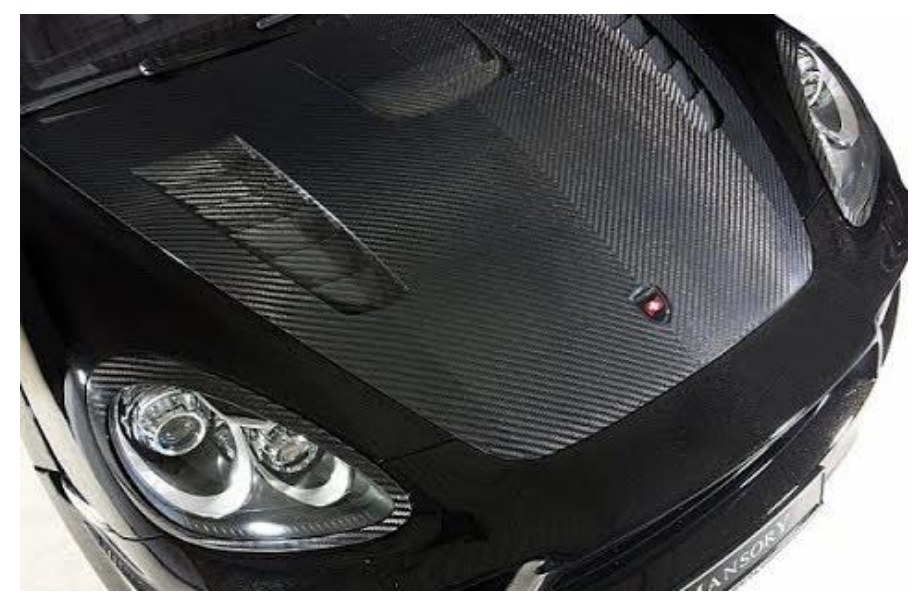

Fig. 4. Image of car bonnet made of carbon fiber [30].

\subsubsection{Coke}

Earlier on, it was noted that the destructive distillation of coal to coal gas results in three useful by-products; coke is the solid by-product of the destructive distillation of coal [6]. From the less useful heavy components of crude oil, coke is produced industrially via the famously delayed coking process which involves high-temperature decomposition of long chain (heavy) hydrocarbons at very slow (well controlled) flow rate and subsequent deposition of the solid in a coker drum [32].

It finds application as electrodes in the manufacture of dry cells; they also serve as good electric conductors $[14,19]$. Coke is also an excellent fuel candidate as it is known to burn with minimal smoke, it used to fire furnaces in the manufacture of steel $[6,33]$.

\subsubsection{Activated carbon}

Simply said, activated carbon is space or porosity bounded by carbon atoms. It refers to amorphous carbon whose microporous structure has been dramatically enhanced chemically or physically [34]. Of all known carbon materials synthesized from renewable sources, it is believed to be the most established [1]. It is made from lignocellulosic precursors such as hardwoods, coconut shell, fruit stones, coals, and synthetic macromolecular systems by first carbonizing the precursor material, followed by activation to maximize its adsorption capacity, via a chemical or physical (thermal) route [35]. Chemical activation is the modification to the carbonizing structure (not after carbonization) by adding chemicals like: phosphoric acid $\left(\mathrm{H}_{3} \mathrm{PO}_{4}\right)$, zinc chloride $\left(\mathrm{ZnCl}_{2}\right)$, nitric acid $\left(\mathrm{HNO}_{3}\right)$, sulphuric acid $\left(\mathrm{H}_{2} \mathrm{SO}_{4}\right)$, sodium hydroxide $(\mathrm{NaOH})$ potassium hydroxide $(\mathrm{KOH})$ or potassium carbonate $\left(\mathrm{K}_{2} \mathrm{CO}_{3}\right)$ [1, 36, 37]; while the physical activation is effected after carbonization by the use of carbon (IV) oxide and/or water vapor as carbon extracting agent(s), via endothermic reaction mechanism(s) as described in detail by Marsh and Rodríguez-Reinoso [34]. Fig. 5 shows a structural model of thermally activated carbon black (a), SEM image of a surface of activated carbon prepared from olive stones (c) [34], and schematic diagram of the allotrope illustrating its porous nature (b) [11]. 
(a)
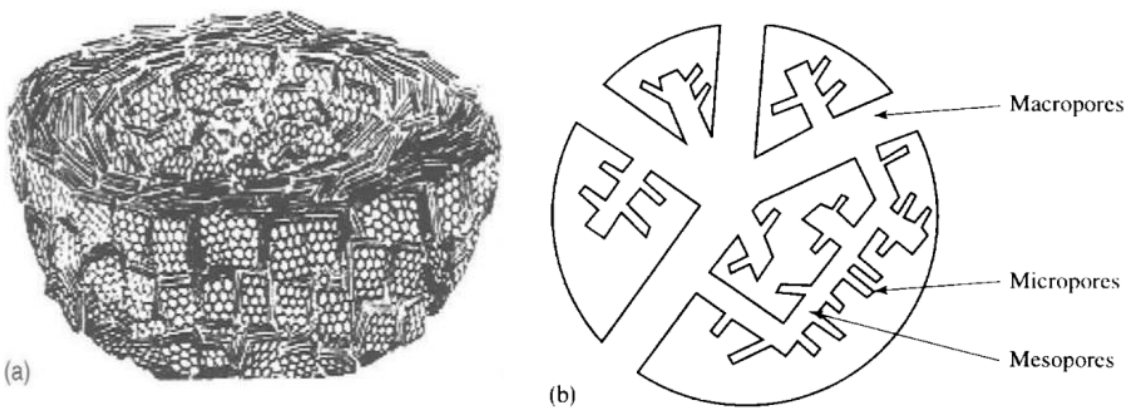

(b)

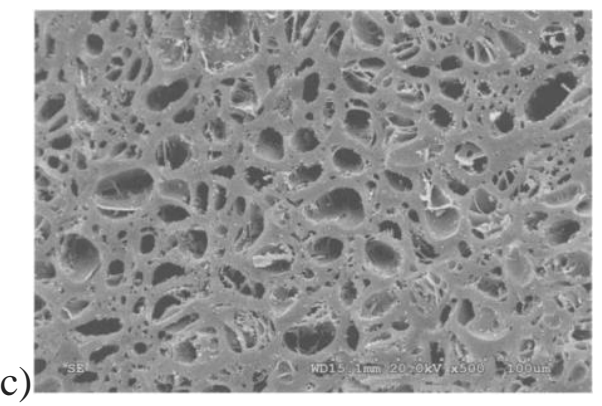

Fig. 5. Structural model of thermally activated carbon black (a), SEM image of a surface of activated carbon prepared from olive stones (c) [34], and schematic diagram of the allotrope illustrating its porous nature (b) [11].

Consequent to the enhanced surface functionality of activated carbon, it has a large surface area to volume ratio and therefore promises to be a perfect adsorbent. As a good adsorbent, it finds application in the removal of poison, reduction of body cholesterol level, rapid reduction of internal gas, intestinal gas, amongst other important applications [35]. Before now, it had been used mainly for water treatment [36, 37]. A more advanced application is the use in energy storage devices to the performance of supercapacitors and electrochemical cells [38].To illustrate how valuable this material has been, a report from the global activated carbon market, as noted by Nasir et al. [1] shows remarkable growth in the carbon black's market.

\subsubsection{Crystalline Allotropes of Carbon}

These are those allotropes with long-range orderliness in the structural atomic arrangement. They include the famous diamond and graphite as well as the trending graphene and graphene derivatives.

\subsubsection{Diamond}

Diamond, a name that connotes: riches, status, allure, glamour, and romance, has been in existence from the ancient history and has been associated with magic, power, and protection $[39,40]$. It is a well-cherished possession, valued far above its real market price, retained as valued heirlooms, and widely used as liquid currency [40]. Naturally, this crystalline allotrope is believed to be formed in the presence of an alloyed iron catalyst at a very high temperature (far above $1200^{\circ} \mathrm{C}$ ) and pressure (about $5.5 \mathrm{GPa}$ ) from plants and animal remains which amassed over billions of years. They occur in two 
primary types of alkaline igneous rock: kimberlites and lamproites, both of which are highly rich in potassium and magnesium $[40,41]$; it is therefore tapped from nature by mining. Today, diamonds of different kinds have been made by man, and they mimic the naturally existing ones. Wentorf and Bovenkerk [41] also noted that there are meteoritic and terrestrial diamonds and that synthetic and natural diamonds can always be distinguished irrespective of the resemblance. According to Thomas and Tropf [42], the early 80s marked the beginning of the investigation of diamond synthesis via a chemical vapor deposition technique, which was led by Japanese researchers and continued for about ten years. In the later period of the 1980s, they succeeded, making it feasible for high-quality diamond which is polycrystalline with a large structure, to be produced by this technique. One of the notable benefits of the chemical vapor deposition process for diamond is the fact that the growth of crystal can be effected at a reduced temperature of about $930{ }^{\circ} \mathrm{C}$ and quite reduced pressure of $2500 \mathrm{~Pa}$. A heated surface whose temperature is adequately controlled serves as a substrate for growth of diamond film which comes from a mixture of hydrogen-light hydrocarbon sources, usually ethyne and methane, and other gases, as a precursor. The gases are partially dissociated with the aid of heating filament, sparks or microwave to yield the active methyl $\left(\mathrm{CH}_{3}\right)$ radical. The employed substrates include oxides of metals, refractory materials or silicon [42].

Diamond, the hardest substance known to man $[6,40]$, is the only known common crystalline allotrope of carbon in which carbon utilizes its whole (4) valence electrons to form strong sigma bonds with fellow carbon atoms; bond formation is possible via $\mathrm{sp}^{3}$ hybridization. The crystal lattice structure of diamond is shown in Fig. 6 [43, 44]; the atomic arrangement is that of unstable face-centered cubic crystal structure, known as a diamond lattice. The overall structure of diamond is isotropic [2]. It has a tetrahedral unit cell due to the $\mathrm{sp}^{3}$ hybridization. To appreciate the diamond lattice in space, refer to the structure animation [45].

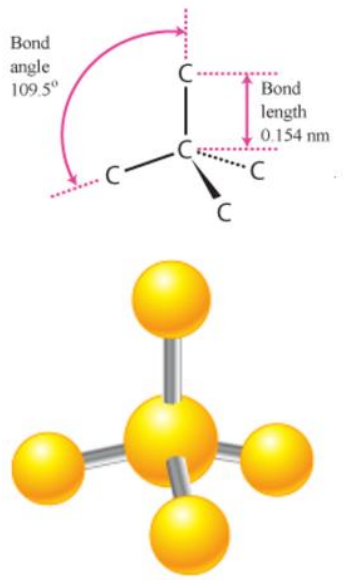

(a)

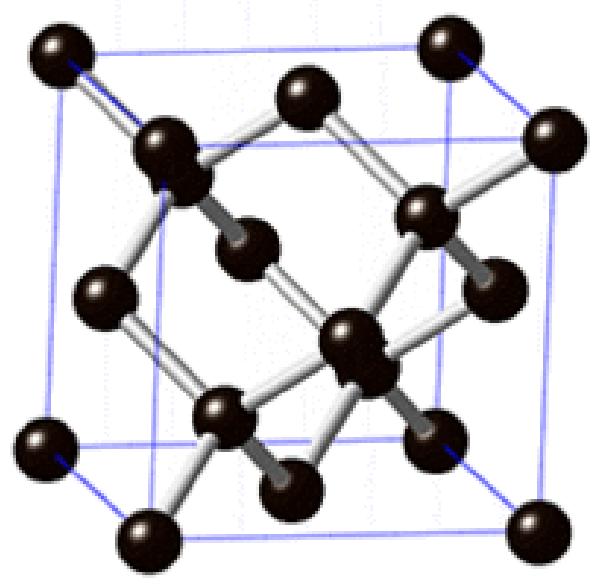

(b)

Fig. 6. Crystal lattice structure of diamond: orientation of a central sp ${ }^{3}$ hybridized carbon atom in space, covalently bonded to four other carbon atoms in a tetrahedral unit cell (a) [43] and the face centered cubic structure (b) [44]. 
In the olden days, the usage of diamond was restricted to ornamental and decorative applications [39]. Nowadays, those applications are scientifically considered as 'abuse', because the material has great potentials which are underutilized by such application. Due to the strong covalent sigma bonds tying the carbon atoms - enabling easy transfer of energy from one atom to another, one of the diamond's outstanding properties is that it has, in comparison to other known materials, the highest thermal conductivity. The heat conductivity of diamond is $2200 \mathrm{~W} /(\mathrm{m} \cdot \mathrm{K})$, while the commonly used conductive metals aluminum (with a conductivity of about $250 \mathrm{~W} /(\mathrm{m} \cdot \mathrm{K})$ ) and copper (with a conductivity of about $400 \mathrm{~W} /(\mathrm{m} \cdot \mathrm{K})$ ), are more than five times poorer thermal conductors $[46,47]$. As a result of its high heat conducting nature, diamond finds application in the manufacture of semiconductors as heat removal medium - preventing the heat-sensitive semiconductors like silicon from overheating [46, 48]. Because all valence electrons are used in forming rigid sigma bonds, the crystal structure of diamond lacks mobile electrons; thereby rendering diamond electrically insulating. Utilizing both the high thermal and poor electric conductivities of diamond, it can be employed as a dielectric material in capacitors that operate at high temperatures up to about $600{ }^{\circ} \mathrm{C}$ [49]. It is resistant to common physical and chemical attacks; it is inert to most acids and alkali, it can withstand heat up to $700{ }^{\circ} \mathrm{C}$, it is the hardest material ever and therefore resistant to wear or abrasion; for these, electronic devices based on diamond should not only be capable of withstanding extremely harsh conditions, but also, they should function well in such atmosphere $[48,50]$. Its physicochemical robustness has generally fetched it the following applications: good material for windows and durable optical devices with wide ranges of photon transmission (due to its special optical properties), good material for making mechanically tough knives, anvil cells, cutting and grinding tools (it is well known that only diamond can cut diamond), good substrate for making heat sinks, and other scientific uses like light detecting [42].

\subsubsection{Graphite}

Dating back to the ancient Greek, the nomenclature, 'graphite' found its origin, courtesy of Abraham G. Werner in the year 1789, from 'graphein', which means to write or express in written characters [51]. Just like diamond and coal, it exists in natural form as fossil and can be mined. Graphite has also been synthesized from various carbon sources just like diamond [52], [53]. Physically, graphite is opaque to light, greyish black colored with unique luster; it is known to be soft and flexible rather than elastic, combines some metallic as well as non-metallic features [54]. It usually appears flaky when examined for morphology using a field emission scanning electron microscope (FESEM), see Fig. 7 [1]. At standard temperature and pressure, it is said to be thermodynamically, the most stable allotrope of carbon [2]. 


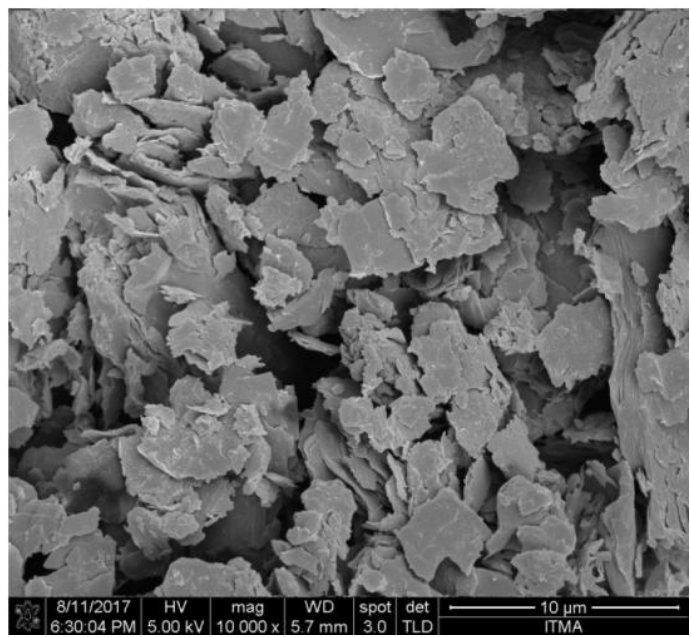

Fig. 7. FE-SEM image of graphite showing the common flaky morphology [1].

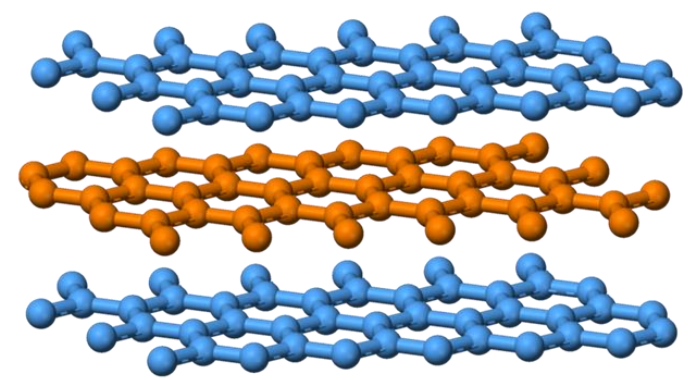

Fig. 8. The stacked crystal structure of graphite [55].

Graphite structure consists stacked layers maintained in position by weak Van der Waals forces. Each layer comprises of flat hexagonal connection of carbon atoms (somewhat like benzene ring); this network of carbon atoms is made possible via $\mathrm{sp}^{2}$ hybridization. Fig. 8 shows the stacked crystal structure of graphite [55]. The presence of one pi electron (which is not so engaged in the formation of the pi bond, unlike the other 3 electrons that are actively involved in rigid sigma bond formation) per carbon atom, makes graphite-rich in delocalized electrons [6]. Graphite crystal lattice is composed of graphene layers stacked anisotropically; for this reason, the full graphite structure is rendered less thermally conducting than expected. It is noteworthy that a graphene layer of graphite, when compared to the thermally high conducting diamond, has the same - if not better - thermal conductivity. Reason being that graphite could have high conductivity along the graphene plane but across this plane, low conductivity; in overall, the conductivity of graphite (average thermal conductivity, integral from all directions) is low [2].

Consequent to the delocalized electrons in the $\mathrm{sp}^{2}$ covalently bonded layers of graphite, the material is an excellent conductor of electricity; therefore, it is used as an electrode in several applications like the electric arc lamp and some electrochemical cells 
$[1,6]$. As a result of the piled or stacked layered structure maintained by weak forces which allow sliding of one layer over another, graphite is soft and slippery offering it the advantage of being employed as a good solid lubricant $[2,6]$. It finds application in the manufacture of dynamos and electric motors (as carbon brush, it maintains dynamic with slip and split ring commutators) due to the lubricating and electric conducting properties. 2.1.2.3. Carbon nanomaterials

These are leading (synthetic) materials in the nano-world, and for this section, their various structures, unique properties and brief of their synthesis techniques would be considered separately, while their applications would be discussed collectively afterward. This class of allotropes of carbon includes graphene ( 2 dimensions), carbon nanotubes (1 dimension), fullerenes (0 dimensions), carbon nanobuds (3 dimensions), carbon nanoparticles (0 dimensions), carbon nanoplatelets ( 2 dimensions), carbon nano-horns (3 dimensions), among others.

\subsection{Graphene and its derivatives}

In 2007, Geim and Novoselov [13] in their article, "The rise of graphene", acclaimed graphene as 'rapidly rising star' in the field of condensed matter physics and science of materials. Zhao et al. [56] regard it as the material science's darling, ever after 2004 when it was discovered by Geim and Novoselov at the University of Manchester. They [13] stated that studies on this material have been on for 60 years. Lots synthesis routes have been developed; some synthesis techniques of importance include: detachment from the stacked graphite structure via micromechanical exfoliation of graphite with the aid of Scotch tape, epitaxial growth and chemical vapour deposition; some other common methods include: reduction of graphene oxide to give the commonly called 'reduced graphene oxide', solvothermal technique and exfoliation of graphite in liquid phase via quenching or via sonication $[9,56]$.

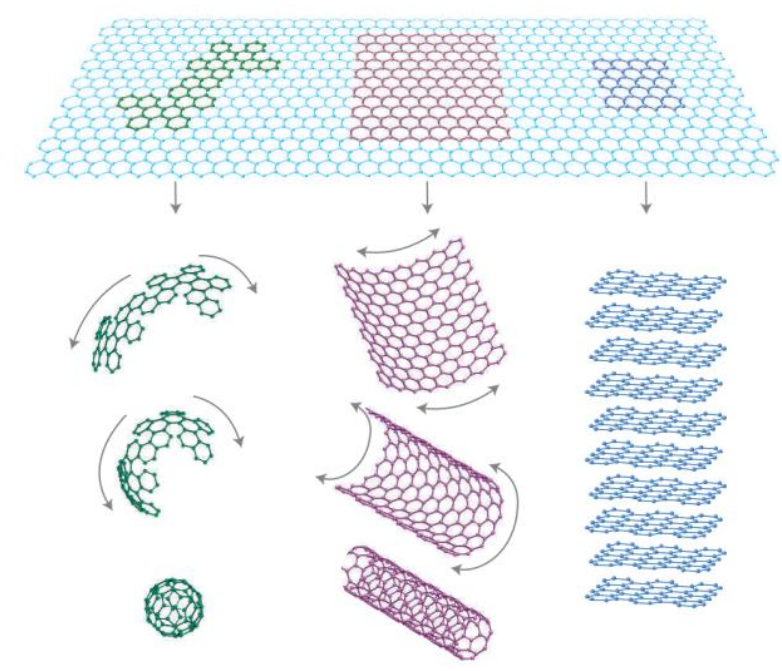

Fig. 9. Graphene a two-dimensionally structured allotrope of carbon as the structural parent material for building the zero-dimensional fullerenes when wrapped up (left), the one-dimensional nanotubes when rolled (middle) and the three-dimensional graphite when stacked in layers [13]. 
Structurally speaking, the almighty material, graphene refers to just single flat (as thick as an atom) layer of carbon atoms with hexagonal lattice structure in two dimensions, usually referred to as the honeycomb lattice. According to Geim and Novoselov [13], the graphene structure when wrapped up to zero dimension yields the structure of another allotrope called fullerene; when rolled to one dimension yields carbon nanotubes and when stacked above one another gives the earlier described structure of graphite; as a result, some authors describe it as two dimensional graphite. Fig 9 shows the structure of graphene, a two-dimensionally structured allotrope of carbon, as the structural parent material for building the zero-dimensional fullerenes when wrapped up, the one-dimensional nanotubes when rolled and the three-dimensional graphite when stacked in layers [13]. Also, Fig. 10 shows a high-resolution transmission electron microscopic image of graphene products that are coated on epoxy resin [56].

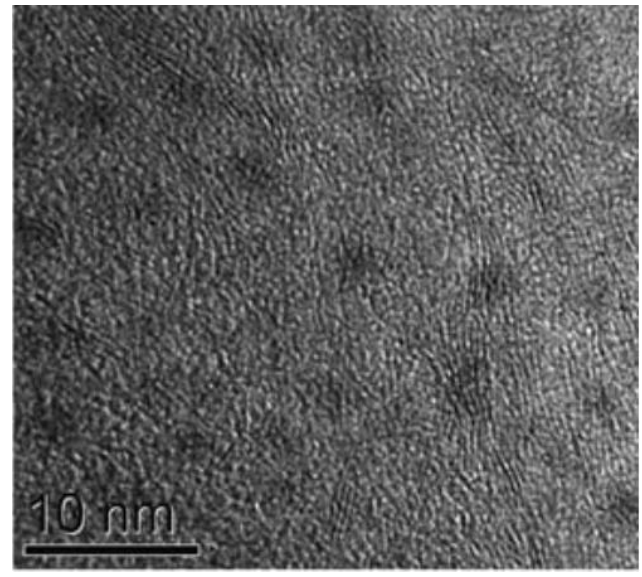

Fig. 10. High-resolution transmission electron microscopic image of graphene products that are coated in epoxy resin [56].

Raccichini et al. [57] state some unique characteristics of graphene to include: very high Brunauer Emmett Teller (BET) surface of $1500 \mathrm{~m}^{2} / \mathrm{g}$ (noted as the highest), heat conductivity of 4840 to $5300 \mathrm{~W} / \mathrm{m} \cdot \mathrm{K}$, electrical conductivity of about $2000 \mathrm{Siemens} / \mathrm{cm}$, it is flexible and elastic with extremely high hardness. It has comparably high thermal conductivity to diamond, as earlier discussed in the case of graphite [2].

Furthermore, graphene has some other critical derivative materials such as graphene oxide, a reduced graphene oxide, which is equivalent to graphene, graphene quantum dots, etc. [1]. Research on graphene led to the discovery of these materials, and they all have their various unique properties.

\subsection{Fullerenes, carbon nanotubes, and nanobuds}

Defining from Oxford Dictionary [58], an allotrope of carbon with a large hollow spherical caged molecule comprising of 60 atoms or even more is termed fullerene. Some fullerene molecules with less than 60 carbon atoms have also been identified [59-61]. Buckminsterfullerene [59-61] (commonly referred as buckyball), a fullerene having 20 hexagonal and 12 pentagonal rings, with 60 carbon atoms $\left(\mathrm{C}_{60}\right)$, each attached at the vertices of the polygons; was the first of its kind to be discovered and named after Richard Buckminster (Bucky) Fuller, in the year 1985, courtesy of Harry Kroto and Richard 
Smalley [1, 62]. The nick-name, buckyball comes from the fact that the structure of the particular fullerene, Buckminsterfullerene resembles a football design, Fig. 11 - hence the name, buckyball [5]. After the buckyball, other crystalline allotropes of carbon with similar structure (be it spherical or elliptical) were named after Fuller. Fig. 12 shows the structure of two members of the fullerene family with 720 carbon atoms [63] and 540 carbon atoms [60]. These spherical structured allotropes are usually synthesized via arc discharge technique using carbon terminals in the inert atmosphere [58].
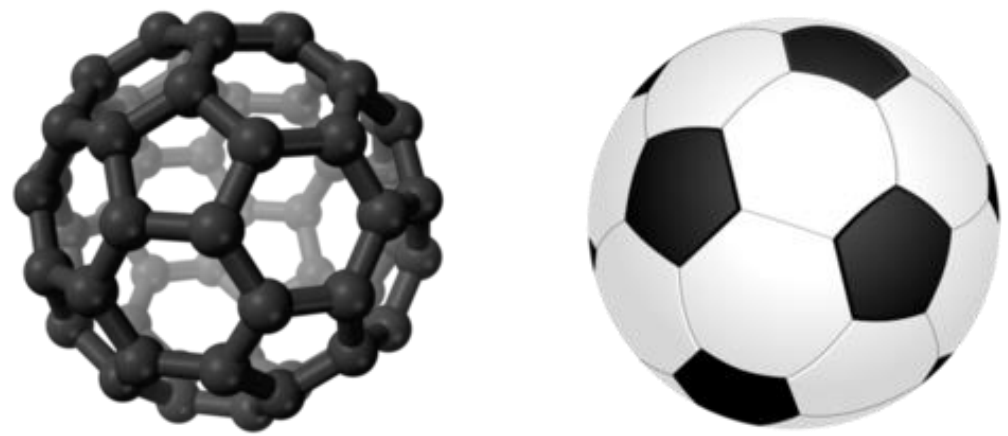

Fig. 11. The resemblance of Buckminsterfullerene to a football design; hence the name, buckyball.

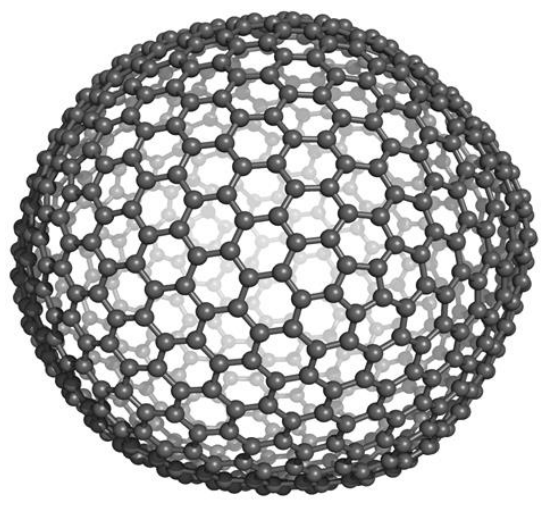

(a)

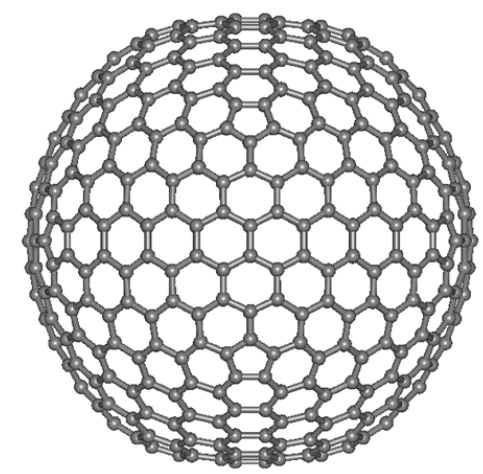

(b)

Fig. 12. Structure of two members of the fullerene family with 720 carbon atoms $(a)$ [63] and 540 carbon atoms (b) [60]. 
(a)

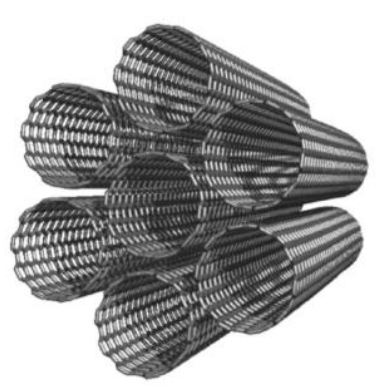

(b)

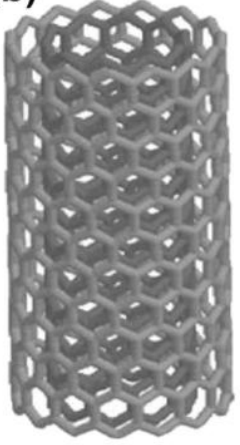

(c)

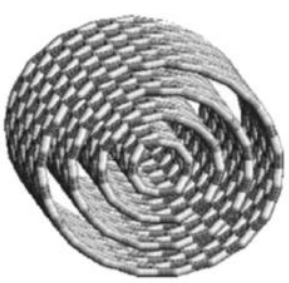

Fig. 13. Bundle of single-walled carbon nanotube (a), a double-walled nanotube (b) and multiple walled nanotubes (c) [2].
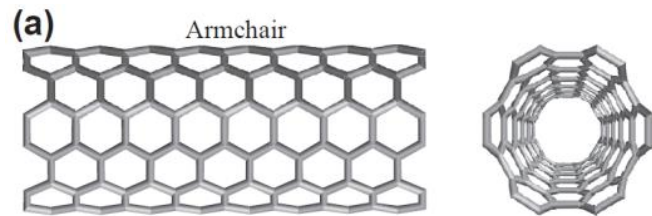

(b)
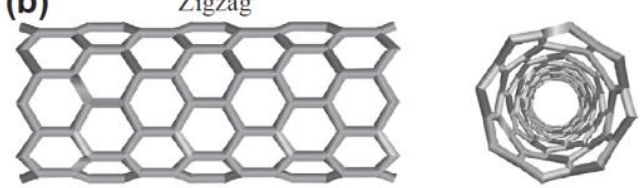

(c)

Chiral
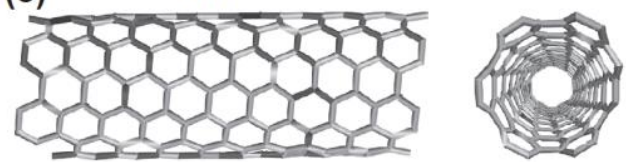

Fig. 14. Structural model of varieties of carbon nanotube: the armchair shape (a), the zigzag (b), and the chiral shaped structure (c) [2].

As for carbon nanotube, it may structurally be regarded as a rolled graphene sheet resulting to a cylinder with the dimension in the characteristic range of a nanotube (diameter between 1 and $100 \mathrm{~nm}$ ), but with unimaginable length to diameter ratio far greater than $10000[64,65]$. Several types of carbon nanotube have been identified, and they include those shown in Fig 13: single-walled carbon nanotubes (a), double walled nanotube (b) and multiple walled nanotubes (c) [2]. A detailed description of the crystal lattice of graphene and the fold up in one dimension to nanotube revealed three possible varieties of carbon nanotube shown in Fig. 14, namely: the armchair shape (a), the zigzag (b), and the chiral shaped structure (c) [2], [66]. The armchair and zigzag structures can be easily distinguished, but the chiral structure may not; chiral carbon nanotube has the hexagons ordered spirally along the tube axis, while for the armchair, the hexagons are ordered straight along the axis. The deposition and growth (synthesis) of this material by 
chemical vapor deposition is detailed by Pang et al. [9] and Wang et al. [65]. It can also be produced via laser ablation technique [67]. The spatially uniform temperature during the synthesis is crucial for ultra-long nanotubes with uniform electrical properties along the length of tubes [65]. However, in reality, it is challenging to synthesize ideally identical tubes; non-hexagonal rings like pentagons and heptagons do exist [68]. These crystal defects cause the ideal cylindrical shape of carbon nanotube to bend, with several other anomalies which were noted by Zhang and $L i$ [66]. Fig. 15 shows some possible structural defects in carbon nanotubes. Interestingly, the resulting deviation in morphology which leads to a shift in properties creates potentials for new applications. Even if considered beneficial, the defects may not be uniform as desired. For nanotubes with structural defects to be useful, there bend morphology and geometry (bend direction, diameter and so on) must be put under control [66].
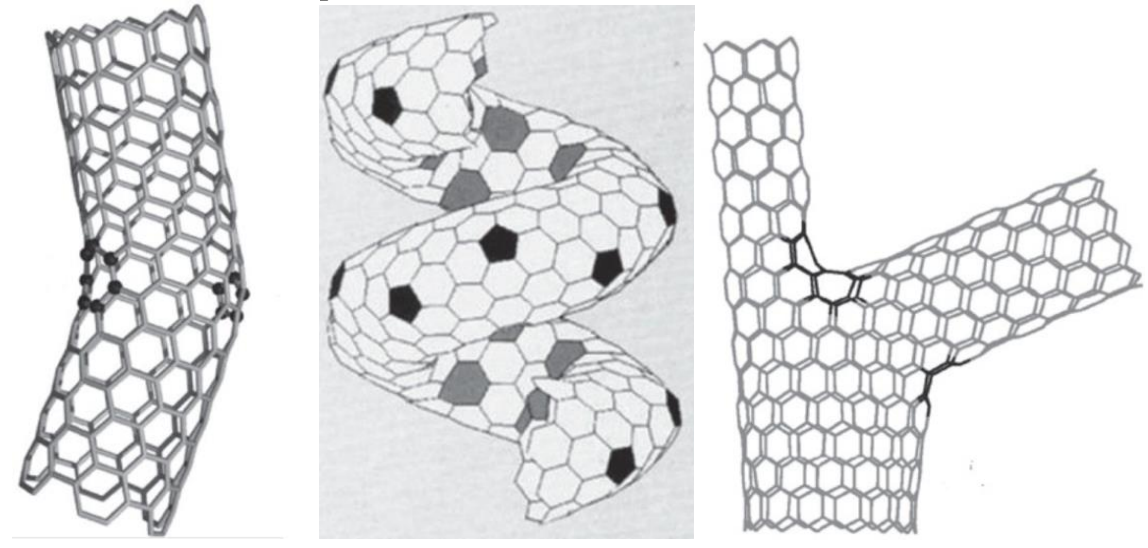

Fig. 15. Some possible structural defects in carbon nanotubes [66].

Furthermore, a hybrid structure of carbon nanotube and fullerene or graphene and fullerene, known as carbon nanobud - courtesy of Nasibulin et al. in 2007 [69] - has been discovered. As a hybrid, carbon nanobud combines the properties of its composite structures (fullerene and graphene or carbon nanotube). Nanobuds of fullerene and carbon nanotube origin may come in two forms; endohedral (when the fullerene structure resides inside the nanotube) - this is also termed carbon peapod [70, 71] - or exohedral (when the fullerene is located outside the tube). Nasibulin et al. [69] discovered exohedral nanobuds using covalently functionalized carbon nanotubes in two different single step continuous methods, in which the fullerenes were formed on Fe particles (as a catalyst) together with single-walled nanotubes during $\mathrm{CO}$ disproportionation. The successful synthesis of nanobuds via treatment using radio frequency plasma was first reported by Duan et al. [61]. Methods for preparation of endohedral and exohedral fullerene and carbon nanotube hybrids by both covalent and non-covalent functionalization of carbon nanotube walls are reported in a review by Vizuete et al. [59].On the other hand, Wu and Zeng [62] proposed the engineering of 'periodic graphene nanobuds', by fusing or covalently bonding buckminsterfullerene onto graphene monolayer in 2008. In 2017, the synthesis of graphene nanobuds by non-covalently anchoring molecules of buckminsterfullerene with the aid of adsorbed pyrene was successfully carried out by Garrido et al. [72]. Fig. 16 shows the theoretical structural models of carbon nanobuds: 
of fullerene and carbon nanotube origin (a) [69] and fullerene and graphene origin, the graphene nanobud (b) [62].
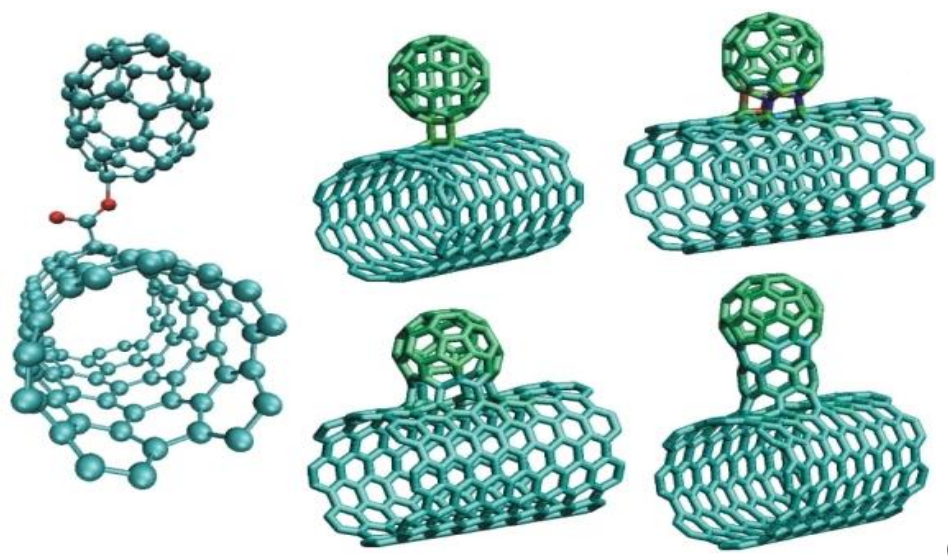

(a)

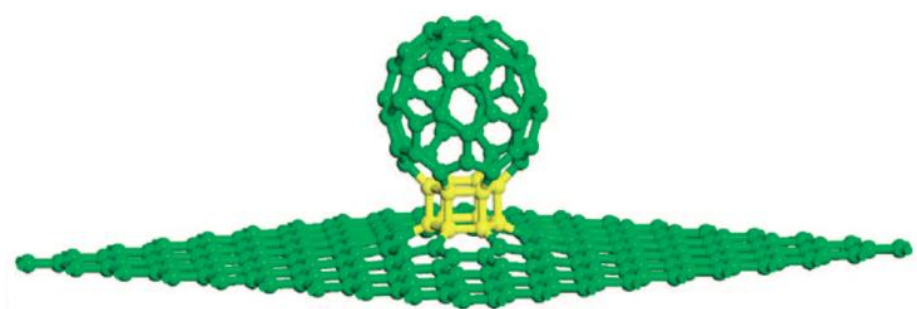

(b)

Fig. 16: Theoretical structural models of carbon nanobuds: of fullerene and carbon nanotube origin (a)[69] and fullerene and graphene origin, the graphene nanobud (b) [62].

Another essential carbon nanostructure of interest is the nanotorus (plural is nanotori). Theoretically, the structure of carbon nanotorus is obtained by bending carbon nanotube into a donut (ring or toroid) shape [67, 73, 74]. Fig 17 shows the structural model of carbon nanotorus [75]. According to Liu and Zhao [68], it is a 0-dimensional nanostructure which may be considered a giant molecule and utilized directly as a nanodevice. Synthesis of this material started with Liu and co-workers in 1997 [76], when they produced carbon nanotorii of diameter range 300 to $500 \mathrm{~nm}$ via laser technique. Afterward, the nanomaterial was identified amidst carbon nanotubes in catalytic synthesis of carbon nanotubes via thermal decomposition of gaseous hydrocarbon precursor [77]. Also, Martel et al. [78], [79] synthesized nanotubes by laser technique and successfully shortened and bent them to nanotorii via ultrasound-aided acid treatment. Till date, several other techniques have been developed for producing this material, and they include synthesis from carbon nanotubes by organic reactions [80], chemical vapor deposition [81], etc. Asides the single-walled nanotorii, double and multi-walled structures are now possible with adequate control of diameter [68]. In all, the carbon nanotorii were verified to be thermodynamically stable. 


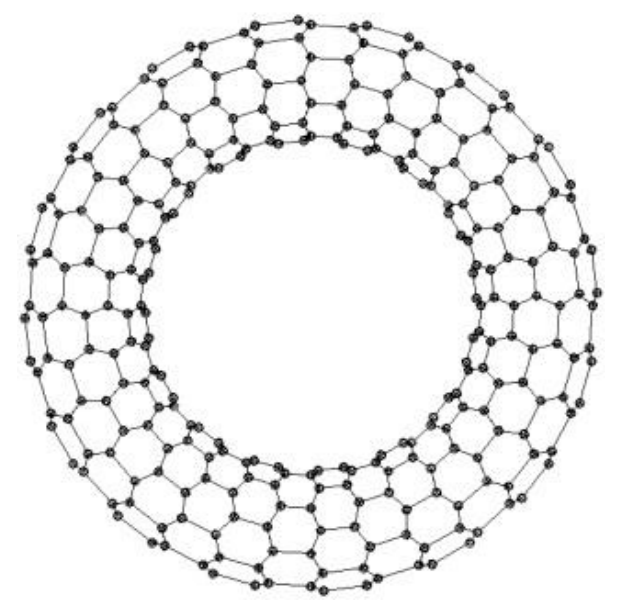

Fig. 17. Structural model of carbon nanotorus [75].

Studies on fullerenes, carbon nanotubes, and their relationship, have been ongoing even before graphene was discovered in 2004 [1]. Based on both experimental and theoretical studies, it has been shown that the nanotubes are one of the strongest known materials with low density $[82,83]$. Field-emission behavior of nanobuds suggest greater advantageous properties than the parent structures alone, or even together without being bonded; for instance, the compact nature of endohedral nanobud may render it more thermally and electrically conducting, while the bud/protrusion on exohedral nanobuds may prevent them from sliding in composites thereby imparting greater materials strength $[64,69]$. It may be realized someday that they are stronger than carbon nanotubes. Endohedral functionalization of carbon nanotubes creates an avenue for manipulating the electronic characteristics of these materials [59]. The structure of carbon nanotorus is noted for its high magnetic property which is reported to be 'magically' about $10^{3}$ times stronger than usual at certainly selected radii [73, 74]. Liu et al. [74] believe that the unexpected or 'magic' properties could be explained by the unusual behavior of the electrons when they move around the ring-shaped structures. However, the electronic properties of nanotorus are not so well understood [73].

\subsection{Some notable applications of carbon nanomaterials}

While other discussed amorphous allotropes of carbon can be used as fuel for generating energy, carbon nanomaterials are far more useful in the energy sector. For energy storage, Ji et al. [38] noted that, "They are considered as attractive materials for hydrogen $\left(\mathrm{H}_{2}\right)$ storage and high-performance electrochemical energy storage devices, such as supercapacitors, rechargeable lithium (Li)-ion batteries, Li-sulfur batteries, Li-air batteries, sodium (Na)-ion batteries, Na-air batteries, zinc ( $\mathrm{Zn}$ )-air batteries, and vanadium redox flow batteries (VRFB), etc.", due to their potential to enhance the lifespan, efficiency, capacity and gravimetric energy density of the devices. For enhancement of fuel cells' performance, electrocatalysts (usually platinum) are used to accelerate the redox reaction [84]. However, platinum, being costly is not suitable for this application. Fei et al. [85], reported that nano-platelets of hydrothermally fabricated quantum dots, synthesized on graphene substrate gave excellent electro-catalytic effect far better than the expensive platinum. As per the application to super-capacitors, Abbas 
et al. [86], Ji et al. [38] and Fam et al. [87] have demonstrated the use of carbon nanotubes and graphene in composite form or as surface coating, for use as electrodes, to boost the capacitance of super-capacitors up to five times their usual values. Nanotubes of carbon have also been used for miniature transistors and highly conducting tiny wires [88].

Again, carbon nanotubes have been found to possess some unique physical and chemical characteristics; hence, it is proposed to serve as transporting medium for varieties of biologically active molecules, like drugs, proteins, and genes when modified appropriately. For example, in the case of drug delivery, it is found that carbon nanotubes are capable of improving drug metabolism, thereby enhancing the therapeutic effect of drugs [89]. Graphene was first used in this regards for delivery of cancer drugs [90].

Furthermore, these materials have also been found wanting in the area of biosensing. Graphene and its derivatives have attractive electrochemical attributes that make them useful as electrode materials in the improvement biomolecules detection. Graphene, for example, has an excellent electrocatalytic effect on hydrogen peroxide and therefore, it is used in making electrodes for biosensors that utilize oxidase enzyme. Consider the case of detecting glucose level in the body using the enzyme, glucose-oxidase as a sensor; the use of graphene electrode material would increase the oxidase activity, i.e., the sensitivity of the biosensor [91]. It is said that graphene has signal amplification ability; for this reason, it has been used together with carbon nano-spheres functionalized alongside multi-enzymes, as a sensitive detector of cancer immune substances, with seven times increase in sensitivity, compared to the response of the bio-sensor without graphene [92].

Unfortunately, the use of nanomaterials of carbon origin in biomedicine is limited as they may give rise to toxicity issues because the toxicity pattern of these materials is yet to be predicted [93]. Consequently, the stated success of carbon nanotubes and the likes in the areas of drug delivery, bio-sensing (diagnosis), gene therapy, etc. is not yet translated to the biomedical field - in other words, those applications are still pending to be used directly on the human body. Jain et al. [93] recommend that caution is taken while handling the 'wonder material', but they still admit based on its high potential for commercial use and clinical trials, that its future in the biomedical field is bright.

The carbon nanomaterials have a high tensile strength about 50 times higher than that of steel, which confers on them the capacity for use in structural applications, usually in composites [82]. In a recent study using graphene nanoplatelets in cement composite by Rehman et al. [94], modified cement composite showed enhanced load carrying capacity and overall failure strain. They were also able to predict response against cracks propagation using cement-graphene composite; consequently, they proposed its use as self-sensing composite material [94]. Detection of flaws in concrete can now be achieved using cement-graphene composite, alongside an improvement in concrete strength. The low density of carbon nanomaterials serves additional benefit because most modern materials are desired to be reliable and portable, rather than bulky.

Again, research on 'mixed matrix membranes' has shown that single and multiwalled carbon nanotubes are very useful in the enhancement of membrane performance; notably, with increased fouling resistance and operation rate per unit membrane area [95].

Also, in agriculture, it is proposed that by adsorbing crop nutrients (fertilizer) onto graphene's surface, the rate of release of nutrients can be controlled to meet the demand of crops and mitigate leaching; and this technique would be environmentally benign [96]. Australian researchers from the University of Adelaide, are currently working to develop 
environmentally safer and cheaper fertilizers using graphene as a carrier due to its high surface area [97]. However, review by Mukherjee et al. [98] reveals that carbon nanomaterials may though be of benefit to crops via enhancement of crop yield, but the use of these materials is also proven harmful, as carbon nanomaterials interaction with plants can cause genetic alteration and acute cytotoxicity. Hence, the application of these materials in agriculture is currently limited.

Also, Katwala [99] reported the use of graphene based material (graphene oxide for the case of plants) for sensing, taking advantage of the variation of conductivity of graphene oxide with water vapor. The developed cheap 'wearable sensors' can be attached to (worn on) the stem, leaves or any desired part of a crop and in turn used to measure water use or loss.

It is noteworthy that graphene has also been found to be an excellent corrosion control agent $[100,101]$.

Nanobuds of carbon nanotube and fullerene origin have been studied for several applications such as use in sensing systems, use in photovoltaic cells; use as a flame retardant in plastics, coatings, textiles; for optical limiting in the field of optoelectronics and nonlinear optics [59]. It is proposed that carbon nanobuds could find many other applications as they may be used for memory devices and for cold electron field emitters (materials which in the high electric field, discharge electrons at ambient temperature); this is a result of the large curved surface of fullerene (the bud) which adapts the nanobud as a better emitter than the flat surfaced nanotube. Many technologies (like those of electron microscopes and flat-panel displays) have their foundation on this cold electron field emission [64].

Several other applications have been proffered based on theoretical studies. For example, by molecular dynamics simulation, Su et al. [70], Wang and Li [71] investigated the applicability of peapods (endohedral nanobud of fullerene and carbon nanotube origin) by quantitatively characterizing the energy dissipation channels in specific peapod structures and found out: that a peapod adapts well as an oscillator; that adjustment of the motion of buckyball at early stage could result in broader tuning range of period (80 to $18 \mathrm{ps)}$ of the oscillator [71]; that nano-oscillators (peapods) have extremely low operating friction and can be easily adapted for generation of impulse [70]. They claim that their results can be realized in the laboratory.

Application of carbon nanomaterials are however not limited to those above; there exist several others: for aerospace materials, defense gadgets, automobile parts, etc. Fig. 18 shows a schematic summary of some applications of carbon nanomaterials (in blue ink) concerning their properties (in red ink) [1]. 


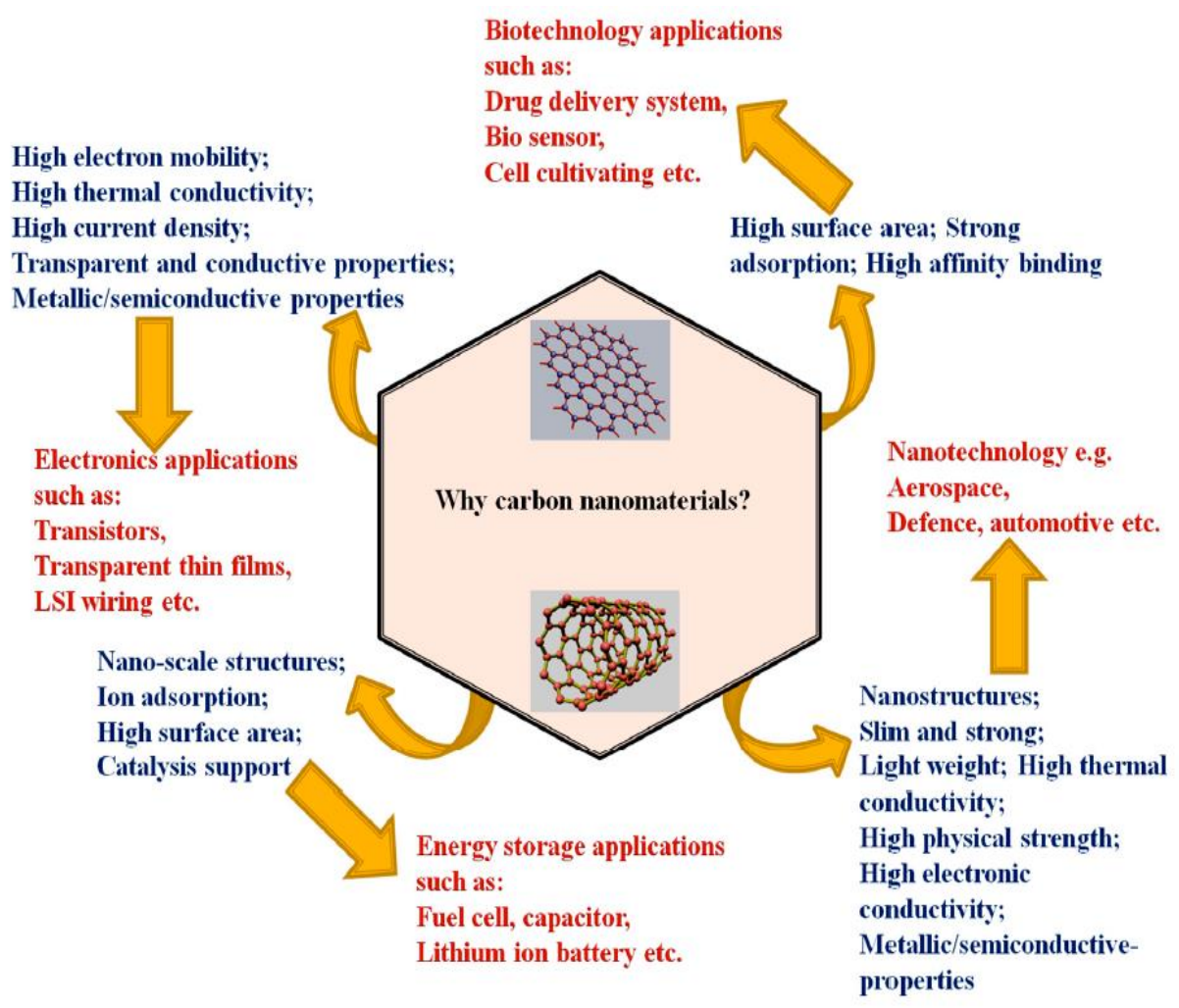

Fig. 18: Schematic summary of applications of carbon nanomaterials (in blue ink) concerning their properties (in red ink) [1].

\section{Conclusion and Recommendation}

Carbon has been treated concerning its various allotropes. The structures, salient properties and following uses of the allotropes were considered. Variation in the structure of carbon, even for a specific allotrope, results in a change in behavior and consequently, may pave the way for new application. The amorphous allotropes proved useful as heat energy sources and adsorbent materials for separation purposes. The crystalline allotropes were described to be more applicable, mainly the nanocrystals which are versatile. Nanocarbon has paved the way for a new trend in research as evidenced by the ever increasing number of articles and patents in its credit, both as a lone material and in the composite form [2]. Of course, some properties of nanomaterials, particularly the mechanical properties such as strength, cannot be assessed directly but from their composites. Based on these, it would be deserving of carbon to conclude this project with the words of Zoltek [27], "The only limit to what carbon can produce is the imagination of the person who intends to use it".

Although the synthesis of graphene from agricultural waste has been tried [102], the major limitation to the production of synthetic nano-carbon is the fact that they are synthesized from non-renewable and non-sustainable hydrocarbons, as precursors. It is 
therefore recommendable that renewable and sustainable sources like biomass, be explored as a commercial alternative with adequate control of crystal defects. The crystal growth control is necessary to extend carbon nanomaterials application to critical areas, notably: biomedicine and agriculture.

\section{Acknowledgment}

The authors acknowledge scholarship support from the Ministry of Higher Education (MOHE) at Egypt-Japan University of Science and Technology, Egypt. Thanks to Solomon Okpako of Adelaide University, Australia for contributing financially to this project. Also, this review paper is a compilation of data, information, and extracts from a variety of sources, primarily web-based with critical sources identified in the references; the content and contribution of these sources are highly acknowledged.

\section{References}

[1] S. Nasir, M. Z. Hussein, Z. Zainal, N. A. Yusof: Materials, 11 (2018) 1-24.

[2] M. Loos, "Allotropes of Carbon and Carbon Nanotubes," in Carbon Nanotube Reinforced Composites, Elsevier. Amsterdam, The Netherlands, 2015, pp. 73-101.

[3] C. J. Allegre, J. Poirier, E. Humler, A. W. Hofmann: Earth Planet Sci Lett., 134 (1995) 515-526.

[4] N. R. Pace: Proc Natl Acad Sci, 98 (2001) 805-808.

[5] CK-12 Chemistry, "Carbon, A Unique Element," FlexBooks, 2012. [Online]. Available: https://www.ck12.org/book/CK-12-Chemistry-Second-Edition/r18/section/ 25.1/. [Accessed: 20-Sep-2018].

[6] O. Y. Ababio, New School Chemistry for Senior Secondary Schools, Revised Ed. Africana-FEP Publishers Limited, 1980.

[7] Y. Zhang and Q. Yin: Proc Natl Acad Sci, 109 (2012) 19579-19583.

[8] Britannica, "Allotropy," Encyclopadia Britannica, inc., 2017. [Online]. Available: https://www.britannica.com/science/allotropy. [Accessed: 19-Sep-2018].

[9] J. Pang, A. Bachmatiuk, I. Ibrahim, L. Fu, and D. Placha: J Mater Sci, 51 (2016) 640667.

[10] M.-M. Titirici et al.: Chem Soc Rev, 44 (2015) 250-290.

[11]F. Rodriguez-reinoso: Carbon N. Y., 36 (1998) 159-175.

[12] M. J. Allen, V. C. Tung, and R. B. Kaner: Chem Rev, 110 (2010) 132-145.

[13] A. K. Geim and K. S. Novoselov: Nat Mater, 6 (2007) 183-191.

[14] Askiitians, “Allotropes of Carbon," 2018. [Online]. Available: https://www.askiitians.com/iit-jee-s-and-p-block-elements/allotropes-of-carbon/.

[Accessed: 22-Sep-2018].

[15] Atomistry, "Element Carbon, C, Non Metal," 2012. [Online]. Available: http://carbon.atomistry.com/. [Accessed: 22-Sep-2018].

[16] T. Frauenheim, G. Jungnickel, T. Kohler, U. Stephan: J Non Cryst Solids, 182 (1995) 186-197.

[17] A. Kouchi, “Amorphous Carbon,” Encycl. Astrobiol., pp. 3-4, 2014.

[18] J. Robertson: Adv Phys, 35 (1986) 317-374.

[19]Passnownow, "amorphous Forms of Carbon," 2018. [Online]. Available: https://passnownow.com/classwork-series-exercises-chemistry-ss1-amorphous-formscarbon/. [Accessed: 22-Sep-2018].

[20] A. Mohammed, A. A. Aboje, M. Auta, M. Jibril: Pelagia Res Libr Adv Appl Sci Res, 3 (2012) 3089-3096. 
[21] W. Roberts, "Current Medical Literature - MEDICINE: On the Verification of SugarTesting in the Urine," INDIAN Med. GAZETTE., p. 144, Apr. 1896.

[22] Atomistry, "Animal Charcoal," 2012. [Online]. Available: http://carbon.atomistry.com/animal_charcoal.html. [Accessed: 22-Sep-2018].

[23] Orion Carbons, "Carbon Black Pigments for Powder Coatings," Orion Engineered Carbons, pp. 1-16, 2014.

[24] Y. Matsuhisa, "Tensile failure of carbon fibers," Handb. Tensile Prop. Text. Tech. Fibres, pp. 574-602, Jan. 2009.

[25] M. INAGAKI, "Carbon Fibers," in New Carbons - Control of Structure and Functions, Elsevier Science, 2000, pp. 82-123.

[26] S. J. Park and M. K. Seo, Element and Processing, vol. 18. Elsevier, 2011.

[27]Zoltek Toray Group, "What is Carbon Fiber?," Zoltek, 2018. [Online]. Available: http://zoltek.com/carbon-fiber/what-is-carbon-fiber/. [Accessed: 22-Sep-2018].

[28] O. Paris and H. Peterlik, "The structure of carbon fibres," Handb. Text. Fibre Struct., pp. 353-377, Jan. 2009.

[29] How Things Made, "How Carbon Fiber Car Parts are Made," YouTube Video, 2017. [Online]. Available: https://www.youtube.com/watch?v=gWuciM7xQt8. [Accessed: 22Sep-2018].

[30] How Things Made, "How Carbon Fiber Car Parts are Made," Google, 2017. [Online]. Available: https://i.ytimg.com/vi/gWuciM7xQt8/hqdefault.jpg. [Accessed: 22Sep-2018].

[31] A. B. Morgan, "Flame retardant fiber-reinforced composites," Handb. Fire Resist. Text., pp. 623-652, Jan. 2013.

[32] J. Adams, "Coking 101 An Introduction to Delayed Coking," Process Engineering Associates. $\quad$ LLC. [Online]. Available: https://www.processengr.com/ppt_presentations/coking_101.pdf.

[33] J. Emsley, The Elements, 3rd ed. Oxford University Press, 1998.

[34] H. Marsh and F. Rodríguez-Reinoso, Characterization of Activated Carbon, 1st ed., no. 1. Elsevier Science \& Technology Books, 2006.

[35]A. A. Peláez-Cid and M. M. M. Teutli-León, Lignocellulosic Precursors Used in the Synthesis of Activated Carbon: Characterization Techniques and Applications in the Wastewater Treatment, 1st ed. InTech: Rijeka, Crotia, 2012.

[36]F.-C. Wu, R.-L. Tseng, and R.-S. Juang, "Preparation of highly microporous carbons from fir wood by KOH activation for adsorption of dyes and phenols from water," Sep. Purif. Technol., vol. 47, no. 1-2, pp. 10-19, Dec. 2005.

[37]R. G. Pereira et al.: Fuel Process Technol, 126 (2014) 476-486.

[38] L. Ji, P. Meduri, V. Agubra, X. Xiao, and M. Alcoutlabi: Adv Energy Mater, 6 (2016) $7-16$.

[39]I. Whiteflash, "Legend of the Rock: A Two Thousand Year History of the Diamond." whiteflash.com, pp. 1-16, 2010.

[40] G. Smith, "The allure , magic and mystery - A brief history of diamonds," J. South African Inst. Min. Metall., no. November, pp. 529-534, 2003.

[41] H. P. Wentorf, R. H. Jr. Bovenkerk: Astrophys J, 134 (1961) 995-1005.

[42] M. E. Thomas and W. J. Tropf: Johns Hopkins APL Tech Dig, 14 (1993) 16-23.

[43] Atomic World, "Different types of carbon," Carbon Nanostructures. [Online] Available: http://hk-phy.org/atomic_world/carbon/carbon01_e.html. [Accessed: 23-Sep2018].

[44] Gisaxs, "Lattice:Diamond," $2016 . \quad$ [Online]. Available: http://gisaxs.com/index.php/Lattice:Diamond. [Accessed: 23-Sep-2018]. 
[45] Brian0918, "Diamond animation," Wikimedia Commons, 2005. [Online]. Available: https://commons.wikimedia.org/wiki/File:Diamond_animation.gif. [Accessed: 23-Sep2018].

[46] S. V. Kidalov, F. M. Shakhov: Materials (Basel), 2 (2009) 2467-2495.

[47] E. A. Ekimov, N. V. Suetin, A. F. Popovich, V. G. Ralchenko: Diam Relat Mater, 17 (2008) 838-843.

[48] B. J. M. Hausmann et al.: Diam Relat Mater, 19 (2010) 621-629.

[49] W. Ebert, M. Adamschik, P. Gluche, A. Flöter, E. Kohn: Diam Relat Mater, 8 (1999) $1875-1877$.

[50]A. Deneuville: Comptes Rendus l'Académie des Sci - Ser IV - Phys, 1 (2000) 8190.

[51]A. G. Conly, "Mining Carbon to Decrease the Carbon Footprint," Scientia, 2017. [Online]. Available: https://www.scientia.global/dr-andrew-g-conly-mining-carbondecrease-carbon-footprint/. [Accessed: 24-Sep-2018].

[52] T. V Thu, Y. Tanizawa, N. H. H. Phuc, P. J. Ko, and A. Sandh, "Synthesis and characterization of graphite nanoplatelets," J. Phys. Conf. Ser., vol. 433, no. conference $1,2013$.

[53] B. G. Krishna and M. J. Rao: Int J Adv Res, 3 (2015) 391-397.

[54] N. Deprez, D. S. McLachlan: J Phys D Appl Phys, 21 (1988) 101-107.

[55]Benjah-bmm27, "Graphite-layers-side-3D-balls," Wikimedia Commons, 2007. [Online]. Available: https://commons.wikimedia.org/wiki/File:Graphite-layers-side-3Dballs.png. [Accessed: 23-Sep-2018].

[56] W. Zhao, M. Fang, F. Wu, H. Wu, L. Wang, G. Chen: J Mater Chem, 20 (2010) 5817-5819.

[57] R. Raccichini, A. Varzi, S. Passerini, B. Scrosati: Nat Mater, 14 (2014) 271-279.

[58] Oxford Dictionary, "fullerene," Oxford University Press, 2018. [Online]. Available: https://en.oxforddictionaries.com/definition/fullerene. [Accessed: 25-Sep-2018].

[59] M. Vizuete, M. Barrejón, M. J. Gómez-Escalonilla, F. Langa: Nanoscale, 4 (2012) 4370-4381.

[60]Michigan State University, “Cn Fullerenes." [Online]. Available: http://www.nanotube.msu.edu/fullerene/fullerene-isomers.html. [Accessed: 25-Sep2018].

[61] S. Duan et al.: RSC Adv, 7 (2017) 21124-21127.

[62]X. Wu and X. C. Zeng: Nano Lett, 9 (2009) 250-256.

[63] "C720 Fullerene," [Online].

Available: https://media.istockphoto.com/photos/fullerene-c720-molecular-structureisolated-on-white-picture-id894935180 [Accessed: 25-Sep-2018].

[64]L. Dorneanu, "New Nanomaterial Forms Nanobuds," Softpedia News, 2007. [Online]. Available: https://news.softpedia.com/news/New-Nanomaterial-FormsNanobuds-50861.shtml. [Accessed: 25-Sep-2018].

[65] X. Wang et al: Nano Lett, 9 (2009) 3137-3141.

[66] M. Zhang, J. Li: Mater Today, 12 (2009) 12-18.

[67] R. Purohit, K. Purohit, S. Rana, R. S. Rana, V. Patel: Procedia Mater Sci, 6 (2014) 716-728.

[68]L. Liu, J. Zhao: "Toroidal and Coiled Carbon Nanotubes," in Syntheses and Applications of Carbon Nanotubes and Their Composites., S. Suzuki, Ed. IntechOpen, 2013.

[69] A. G. Nasibulin et al.: Nat Nanotechnol, 2 (2007) 156-161.

[70]H. Su, W. A. Goddard, Y. Zhao: Nanotechnology, 17 (2006) 5691-5695. 
[71] M. Wang, C. M. Li: Nanotechnology, 21 (2009) 035704.

[72] M. Garrido et al.: Chem Commun, 53 (2017) 12402-12405.

[73] IOP Publishing, “Nanotorus' nets giant magnetic moment," Physics World Nanomaterials, 2002. [Online]. Available: https://physicsworld.com/a/nanotorus-netsgiant-magnetic-moment/. [Accessed: 29-Sep-2018].

[74]L. Liu, G. Y. Guo, C. S. Jayanthi, S. Y. Wu: Phys Rev Lett, 88 (2002) 21720612172064.

[75] M. H. Khalifeh, H. Yousefi-Azari, A. R. Ashrafi: Discret Appl Math, 157 (2009) 804-811.

[76] J. Liu et al.: Nature, 385 (1997) 780-781.

[77] M. Ahlskog et al.: Chem Phys Lett, 300 (1999) 202-206.

[78] R. Martel, H. R. Shea, P. Avouris: Nature, 398 (1999) 299.

[79] R. Martel, H. R. Shea, P. Avouris: J Phys Chem B, 103 (1999) 7551-7556.

[80] M. Sano, A. Kamino, J. Okamura, S. Shinkai: Science (80-. ), 293 (2001) 1299-1301.

[81]L. Song et al.: Adv Mater, 18 (2006) 1817-1821.

[82] Y. Li et al.: Carbon N. Y., 43 (2005) 31-35.

[83]Z. Qin, Q.-H. Qin, X.-Q. Feng: Phys Lett A, 372 (2008) 6661-6666.

[84] R. R. Adzic et al.: Top Catal, 46 (2007) 249-262.

[85]H. Fei et al.: ACS Nano, 8 (2014) 10837-10843.

[86] S. M. Abbas, S. T. Hussain, S. Ali, N. Ahmad, N. Ali, S. Abbas: J Mater Sci, 48 (2013) 5429-5436.

[87]D. W. H. Fam et al.: J Mater Sci, 50 (2015) 6578-6585.

[88]Zenblade 93, "Carbon nanotube," SlideShare, 2010. [Online]. Available: https://www.slideshare.net/Zenblade/carbon-nanotube/1. [Accessed: 26-Sep-2018].

[89] H. Sun, P. She, G. Lu, K. Xu, W. Zhang, Z. Liu: J Mater Sci, 49 (2014) 6845-6854. [90]Zhuang Liu, J. T. Robinson, X. Sun, H. Dai: J Am Chem Soc, 130 (2008) 1087610877.

[91] X. Kang, J. Wang, H. Wu, I. A. Aksay, J. Liu, Y. Lin: Biosens Bioelectron, 25 (2009) 901-905.

[92]Dan Du et al.: Anal Chem, 82 (2010) 2989-2995.

[93] S. Jain, S. R. Singh, S. Pillai: J Nanomed Nanotechnol, 3 (2012) 2.

[94] S. K. U. Rehman, Z. Ibrahim, S. A. Memon, M. F. Javed, R. A. Khushnood: Sustain, 9 (2017) 1-20.

[95] B. Van der Bruggen: ISRN Nanotechnol, 2012 (2012) 1-17.

[96] M. Foley, "Graphene for fertiliser focus of agtech research," Farm Online News, 2018. [Online]. Available: https://www.farmonline.com.au/story/5292869/super-strongmiracle-material-to-boost-farm-fertiliser/. [Accessed: 25-Sep-2018].

[97] The University of Adelaide, "Graphene promise for more efficient fertilizers," ScienceDaily, 2018. [Online]. Available: www.sciencedaily.com/releases/2018/03/180307100539.htm. [Accessed: 25-Sep-2018]. [98] A. Mukherjee, S. Majumdar, A. D. Servin, L. Pagano, O. P. Dhankher, and J. C. White: Front Plant Sci, 7 (2016) 1-16.

[99] A. Katwala, “Graphene 'tattoos' for plants enable real-time farming data," Institution of Mechanical Engineers Engineering News, 2018. [Online]. Available: https://www.imeche.org/news/news-article/graphene-'tattoos'-for-plants-enable-realtime-farming-data. [Accessed: 25-Sep-2018].

[100] K. S. Aneja, H. L. M. Böhm, A. S. Khanna, S. Böhm: FlatChem, 1 (2017) 11 19.

[101] J. Hu, Y. Ji, Y. Shi: Ann Mater Sci Eng, 1 (2014) 1-16. 
[102] R. Peleg, "Graphene from agricultural waste," Graphene-info, 2015. [Online]. Available: https://www.graphene-info.com/graphene-agricultural-waste. [Accessed: 25Sep-2018].

\section{(c) (i) Creative Commons License}

This work is licensed under a Creative Commons Attribution 4.0 International License. 